\title{
UNIVERSIDADE FEDERAL DO PARANÁ
}

Programa de Especialização em Prótese Dentária

REGINA MARIA HELEN COT MARCOS

ANÁLISE COMPARATIVA DE DOIS PRODUTOS DE HIGIENIZAÇÃO DE PRÓTESES TOTAIS NA REMOÇÃO DO BIOFILME

\author{
Curitiba - PR
}

2011 


\title{
REGINA MARIA HELEN COT MARCOS
}

\section{ANÁLISE COMPARATIVA DE DOIS PRODUTOS DE HIGIENIZAÇÃO DE PRÓTESES TOTAIS NA REMOÇÃO DO BIOFILME}

\author{
Projeto de Pesquisa apresentado ao Programa de \\ Especialização em Prótese Dentária da Universidade \\ Federal do Paraná como parte dos requisitos para \\ obtenção do título de Especialista em Prótese Dentária. \\ Orientador: Prof. Dr. Nerildo Luiz Ulbrich \\ Co-orientadora : Prof ${ }^{a}$. Dr ${ }^{\mathrm{a}}$. Ana Paula Gebert de O. Franco \\ Coordenador: Prof. Dr. Marcio José Fraxino Bindo
}

Curitiba - PR

2011 


\title{
ANÁLISE COMPARATIVA DA EFICÁCIA DE DOIS PRODUTOS DE HIGIENIZAÇÃO DE PRÓTESES TOTAIS NA REMOÇÃO DO BIOFILME
}

\author{
Regina Maria H.C. Marcos \\ Aluna do programa de especialização em Prótese Dentária ,UFPR, Curitiba (PR)reginahcmarcos@terra.com.br \\ Nerildo Luiz Ulbrich \\ Prof. Dr. em Processos Biotecnológicos pela UFPR, Curitiba (PR) nlulbrich@gmail.com \\ Ana Paula Gebert de Oliveira Franco \\ Prof. Dr Em Dentística pela PUCPR, Curitiba (PR) anagebert@ig.com.br \\ Marcio José Fraxino Bindo \\ Dr. em Prótese Dentária pela USP, São Paulo (SP), Coordenador do Curso de Prótese Dentária da UFPR,Curitiba (PR) \\ mbindo@gmailcom
}

\section{RESUMO}

Objetivo: O objetivo do estudo foi comparar a eficácia de quatro métodos de higienização para próteses totais na redução de placa bacteriana.

Método: Foram selecionados 20 pacientes portadores de próteses totais superiores. As próteses foram coradas com fuccina básica Replak (Dentisply) e, posteriormente, divididas em 2 grupos de acordo com as soluções de higiene: Grupo 1- Corega Tabs(CT); Grupo 2- Hipoclorito de sódio(HS) 2,5\%. No Grupo 1 as próteses foram submersas em $250 \mathrm{~mL}$ de água destilada +1 pastilha de Corega Tabs e no Grupo $2 \mathrm{em} 250 \mathrm{~mL}$ de água destilada $+10 \mathrm{ml}$ de hipoclorito de sódio a $2,5 \%$ por 5 minutos. Após a imersão foi realizada a escovação da porção interna das próteses por 1 minuto. As bases internas das próteses foram coradas e fotografadas após os períodos inicial, imersão e imersão + escovação, e em seguida, avaliada a quantidade de placa bacteriana pelo método da contagem de pontos. Os dados foram analisados pelos testes de t-Student, ANOVA e múltiplas comparações de Tukey HSD.

Resultados: Foram encontradas diferenças significativas entre a quantidade de placa bacteriana inicial e após imersão + escovação para ambos os grupos (CT: 40,12 \pm 22 ,44 e $10,92 \pm 11,39$; HS:40,64 $\pm 24,12$ e 13,06 $\pm 11,08$, respectivamente) ( $p<0,05)$. Não foram encontradas diferenças entre os Grupos 1 e 2 para nenhuma condição teste (inicial, imersão e imersão + escovação) ( $p>0,05)$.

Conclusão: CT e HS não apresentaram diferenças relacionadas à eficiência na remoção de placa bacteriana. O método de imersão + escovação mostrou-se o mais eficiente na remoção de placa bacteriana em próteses totais superiores.

Palavras chaves: prótese total, placa bacteriana, higienização. 


\section{ABSTRACT}

Objective: The objective of this study was to compare the effectiveness of four methods for cleaning dentures in reducing plaque.

Method: We selected 20 patients with maxillary dentures. The prostheses were stained with basic fuccina Replak (Dentisply) and then divided into two groups according to the hygiene solutions: Group 1 - Corega Tabs(CT), Group 2 - 2.5\% sodium hypochlorite(HS). In Group 1 the dentures were submerged in $250 \mathrm{ml}$ of water + Corega Tabs and Group 2 in $250 \mathrm{ml}$ of water $+10 \mathrm{ml}$ of sodium hypochlorite $2.5 \%$ for 5 minutes. After soaking was done brushing the inner portion of the prosthesis for 1 minute. The foundations of internal prostheses were stained and photographed after the initial period, immersion and immersion + brushing, and then evaluated the amount of plaque by the method of scoring. Data were analyzed by Student's t tests, ANOVA and Turkey HSD multiple comparisons.

Results: Significant differences were found between the amount of plaque and initial immersion + brushing for both groups (CT: $40.12 \pm 22.44$ and $10.92 \pm 11.39$; HS: $40.64 \pm$ 24.12 and $13.06 \pm 11.08$, respectively) $(p<0.05)$. No differences were found between Groups 1 and 2 test for any condition (initial immersion and immersion brushing + ) $(p>$ 0.05).

Conclusion: CT and HS showed no differences related to the efficiency in removing plaque. The immersion method + brushing proved to be the most efficient at removing plaque maxillary denture.

Keywords: total prosthesis, bacterial plaque, cleansing. 


\section{INTRODUÇÃO}

As próteses totais removíveis fazem parte ainda de muitos planos de tratamento para pacientes de terceira idade, mesmo com a evolução da implantodontia. A higiene das próteses é um fator muito importante no que se refere à prevenção de doenças cardíacas e pulmonares em pacientes idosos ( Santana et al.;1992 /Nikawa et al., 1999).

A limitação das ações de saúde bucal para adultos e idosos no Brasil, faz com que suas necessidades de tratamento se acumulem, acarretando perdas dentárias prematuras e grande demanda por tratamentos especializados como os protéticos (ALLEGRETTI E SANTOS, 2008). De acordo com o levantamento epidemiológico do Ministério da Saúde SB Brasil, adultos e idosos apresentaram, respectivamente, médias de 20 e 28 dentes cariados, perdidos ou restaurados (índice CPO-D). O componente perdido foi o responsável por $66 \%$ e $93 \%$ do valor do CPO-D nestes grupos. Apesar da demanda acumulada, a utilização de serviços odontológicos é considerada baixa, principalmente entre os idosos. De acordo com o Ministério da Saúde (2003), os resultados da Saúde Bucal - Brasil indicaram que este grupo populacional apresentou a menor taxa de utilização recente dos serviços odontológicos, sendo que apenas $16,8 \%$ dos idosos relataram haver consultado o dentista há menos de um ano, versus $37,6 \%$ dos adultos.

A população idosa vem crescendo nos países desenvolvidos e em desenvolvimento. No Brasil o índice de envelhecimento aponta para mudanças na estrutura etária da população brasileira. Em 2008, para cada grupo de 100 crianças de 0 a 14 anos existiam 24,7 idosos com 65 anos ou mais. A estimativa realizada pelo CENSO 2010 é que em 2050, para cada 100 crianças de 0 a 14 anos existirão 172,7 idosos.

O cuidado com a saúde bucal dos idosos promove a melhoria da eficiência mastigatória, correto consumo de dieta e, consequentemente, melhoria da auto-estima e vida social mais intensa (França e Souza, 2003).

Os cirurgiões dentistas, muitas vezes, se esquecem da importância de orientar os pacientes quanto à manutenção e higienização dos aparelhos protéticos.

Existem poucos estudos na literatura sobre a eficácia dos meios de higiene para aparelhos protéticos removíveis (FERNANDEZ et al.,2002; ZANIQUELLI et al.,2002; PARANHOS et al.,2002).

O objetivo desse estudo foi comparar a eficácia de quatro métodos de higienização para próteses totais na redução de placa bacteriana. 


\section{MATERIAL E MÉTODOS}

Foram selecionados 20 pacientes portadores de próteses totais superiores, cujas bases estivessem inteiras, na disciplina de Prótese Total da Universidade Federal do Paraná. Os pacientes voluntários à pesquisa receberam um termo de consentimento informado aprovado pelo Comitê de Ética sob o número 000119/2009. Posteriormente, foram coletadas as próteses superiores, lavadas em água corrente por cinco segundos e secas com jato de ar por dez segundos. Foram coradas com evidenciador de placa bacteriana Replak (Dentsply Caulk, Milford, DE, USA) (Fig. 1) com o auxílio de conta gotas, por trinta segundos; em seguida enxaguadas novamente por cinco segundos, secas com jato de ar por dez segundos e fotografadas. Posteriormente, as próteses foram divididas randomicamente em dois grupos: Grupo 1: imersão em solução com $250 \mathrm{~mL}$ de água destilada +1 pastilha de Corega Tabs (Figs.2 e 3); Grupo 2: imersão em solução de $250 \mathrm{~mL}$ de água destilada $+10 \mathrm{ml}$ Hipoclorito de sódio a 2,5\% (Figs. 4 e 5 ). Depois da imersão as próteses foram coradas e fotografadas. Posteriormente, as superfícies internas das bases das próteses foram escovadas, pelo mesmo operador, com escova dental macia (Bitufo - IPH\&C Itupeva - SP) por 1 minuto (Fig. 6), coradas novamente e fotografadas.

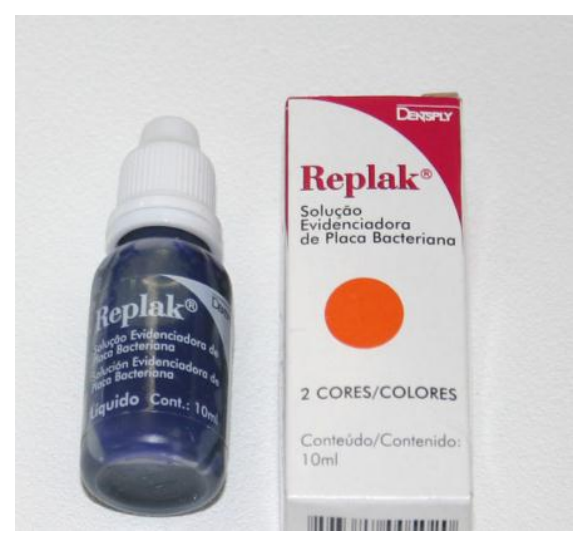

Fig.1. Coranta à base de fuccina básica.

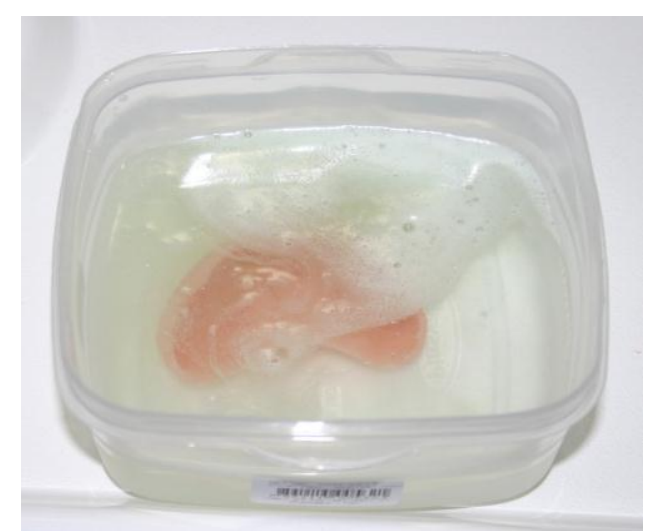

Fig.2.Imersão em solução com 1 pastilha de Corega Tabs em $250 \mathrm{ml}$ de água destilada.

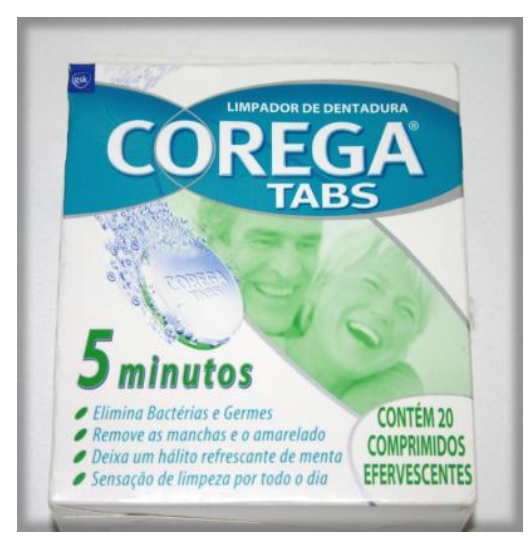

Fig.3. Corega Tabs 


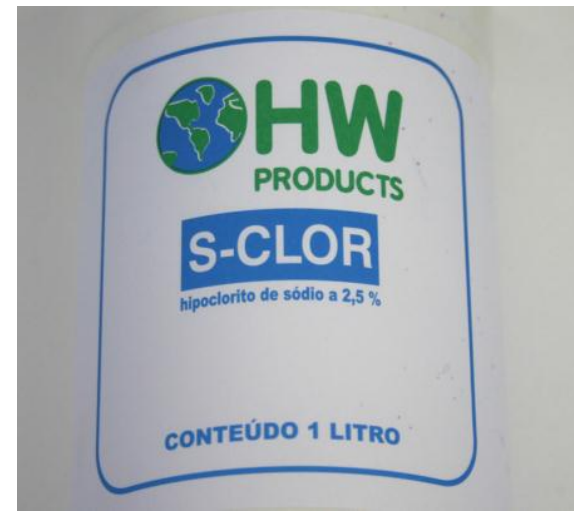

Fig.4. Imersão em solução de hipoclorito de sódio $2,5 \%$.

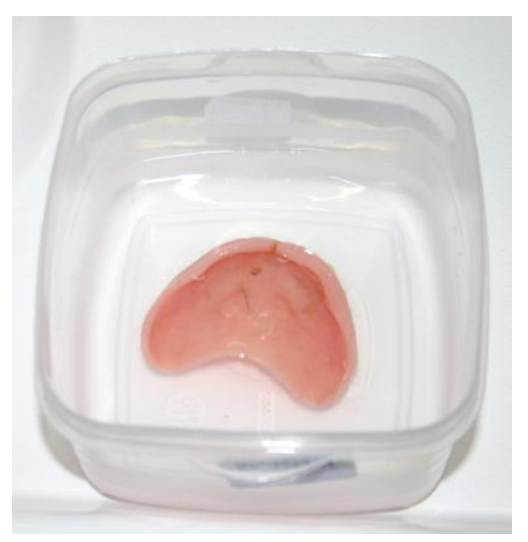

Fig.5. Imersão em solução de hipoclorito de sódio $2,5 \%$ em $250 \mathrm{ml}$ de água destilada .

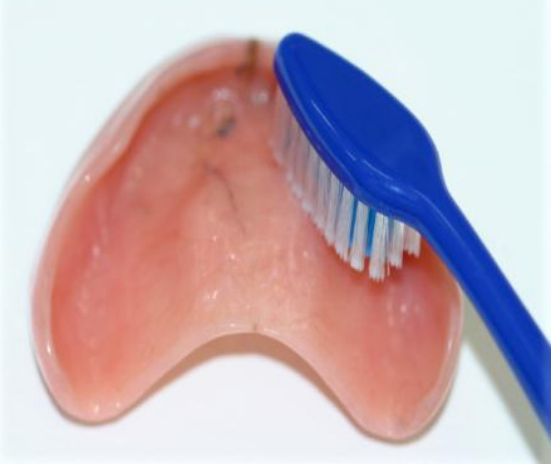

Fig. 6. Escovação.

As substâncias de higiene utilizadas no estudo estão descritos na tabela 1.

Tabela 1. Substâncias de higiene utilizadas no estudo.

\begin{tabular}{|c|l|l|l|}
\hline $\begin{array}{c}\text { PRODUTO DE } \\
\text { HIGIÊNE }\end{array}$ & FABRICANTE & \multicolumn{1}{|c|}{ COMPOSIÇÃo } & NÚMERO DE SÉRIE \\
\hline COREGA TABS & Glaxo Smith kline & $\begin{array}{l}\text { Bicarbonato de sódio, ácido cítrico, } \\
\text { persulfato de potássio, perborato de sódio, } \\
\text { Benzoato de sódio, polifosfato de sódio, } \\
\text { polietilenoglicol 8000, laurilsulfoacetato de } \\
\text { sódio, coliporímero de acetato de vinil, } \\
\text { estearato de sódio, mentol, aromatizantes e } \\
\text { corantes. }\end{array}$ & LMEO31OV1 \\
\hline HIPOCLORITO DE \\
SóDIO 2,5\% & $\begin{array}{l}\text { Marmo indústria } \\
\text { e comércio Ltda }\end{array}$ & $\begin{array}{l}\text { Hipoclorito de sódio, estabilizante de água } \\
\text { e água deionizada. }\end{array}$ & Não consta no \\
produto.
\end{tabular}

As superfícies internas das bases das próteses foram fotografadas após aplicação inicial do corante, após imersão nos antissépticos e após imersão + escovação com uma máquina fotográfica semi-profissional (Canon Eos 6.1 Mega pixels/ Canon) em ângulo de 45․ Em seguida, as imagens foram exportadas para o programa AUTO-CAD 2010, onde realizou-se a medição da área $\left(\mathrm{mm}^{2}\right)$ das superfícies fotografadas, através de uma malha dividida de $5 \mathrm{~mm} \times 5 \mathrm{~mm}$. Após este procedimento, foram feitas contagens do número total de quadrados da base da prótese e do número de quadrados corados após evidenciação de placa, a imersão e a imersão + escovação (Figs. 8 a 13). 
Os resultados foram analisados estatisticamente por meio do teste de normalidade Shapiro-Wilk, de teste de homogeneidade de Levene, ANOVA um critério e teste de múltiplas comparações de Tukey HSD.

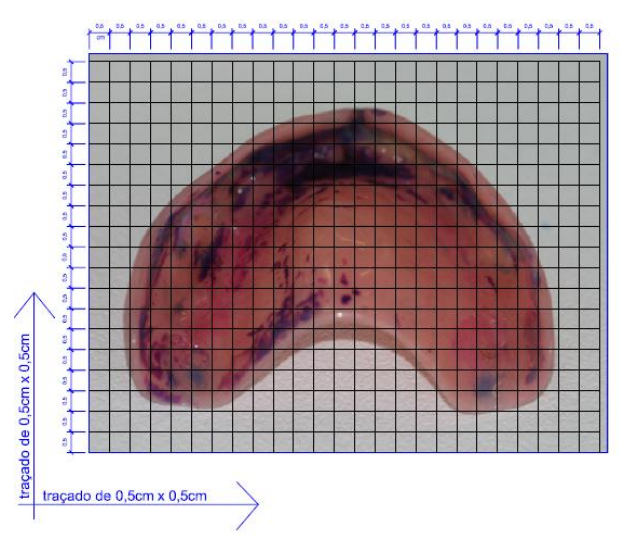

Fig. 8. Evidenciação de placa inicial. Malha de $0,5 \times 0,5 \mathrm{~cm}$.

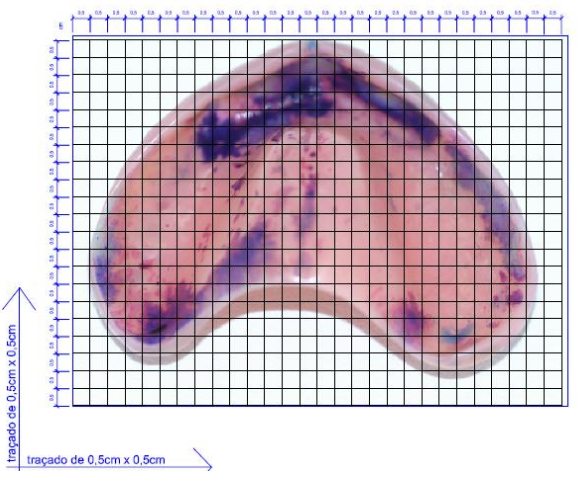

Fig. 11. Evidenciação de placa inicial.

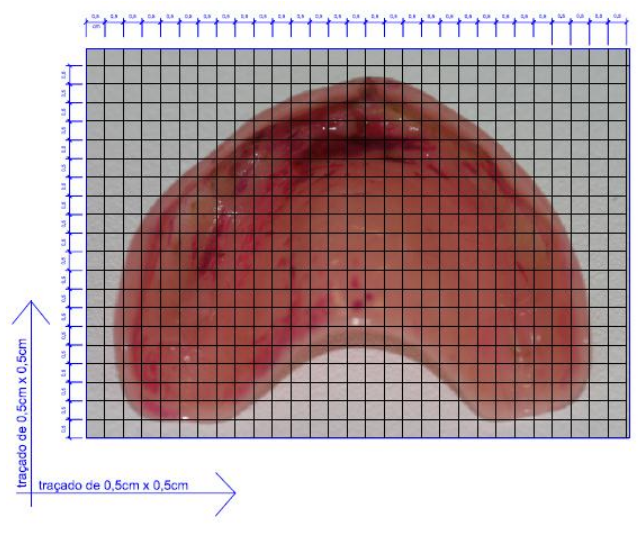

Fig. 9. Após imersão em solução de Corega Tabs.

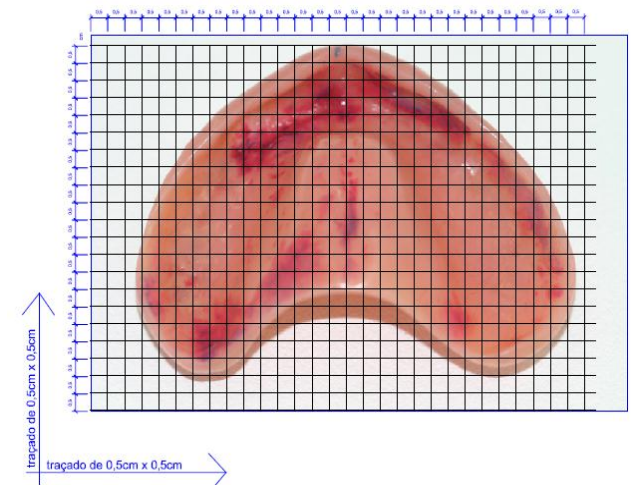

Fig. 12. Após imersão em solução de hipoclorito de Sódio - 2,5\%

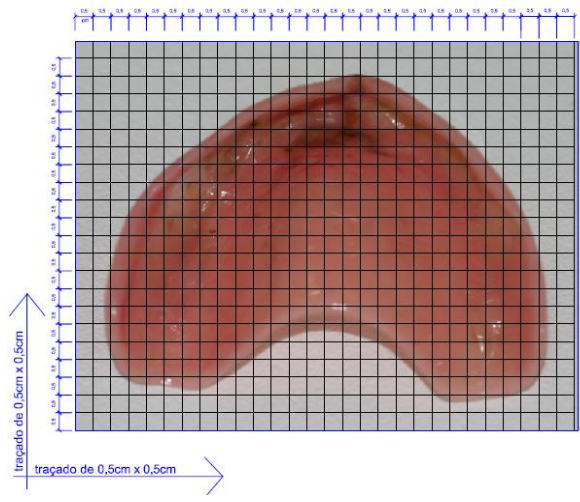

Fig. 10. Após imersão em solução com Corega Tabs + escovação.

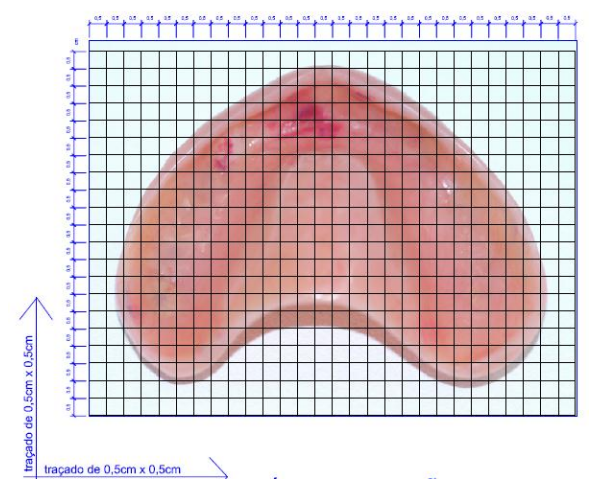

Fig. 13. Após imersão em solução de hipoclorito de sódio $2,5 \%$ + escovação. 


\section{RESULTADOS}

Para esta pesquisa foi utilizado o teste de normalidade de Shapiro-Wilk que indicou distribuição normal $(p>0,05)$. O teste de homogeneidade de variâncias de Levene apresentou homogeneidade segundo a condição teste, a condição da prótese e condição teste $x$ condição da prótese $(p>0,05)$. $O$ teste t Student para valores médios da contagem total antes da medição da porcentagem de placa bacteriana não apresentou diferenças significativas segundo a condição teste $(p>0,05)$. O teste ANOVA um critério para a condição teste, não demonstrou diferenças estatísticas significativas entre solução de Corega Tabs e de Hipoclorito de sódio 2,5\%. O teste de múltiplas comparações de Tukey HSD revelou diferenças significativas entre a porcentagem inicial de placa bacteriana e após imersão associada à escovação .

Quando se realizou a comparação entre os espécimes submetidos às soluções de Corega Tabs e Hipoclorito de sódio 2,5\% não foram observadas diferenças significativas. Para ambos os grupos, Corega Tabs e Hipoclorito de sódio 2,5\%, na comparação entre as formas de higiene, observou-se que as porcentagens de placa bacteriana inicial e após a imersão diferiram estatisticamente da contagem final (imersão + escovação) $(p<0,05)$, porém não diferiram entre si, como mostra a tabela 2.

Tabela 2. Valores de média (desvio padrão) das porcentagens de placa bacteriana para as diferentes condições de teste.

\begin{tabular}{|l|c|c|}
\hline $\begin{array}{l}\text { Produtos de higiene/ } \\
\text { Condição teste }\end{array}$ & $\begin{array}{c}\text { Solução de Corega } \\
\text { Tabs }\end{array}$ & $\begin{array}{c}\text { Solução de } \\
\text { Hipoclorito de } \\
\text { sódio } 2,5 \%\end{array}$ \\
\hline Inicial & $40,12(22,44) \mathrm{A}, \mathrm{a}$ & $40,64(24,12) \mathrm{A}, \mathrm{a}$ \\
\hline Imersão & $27,88(21,43) \mathrm{A}, \mathrm{ab}$ & $27,00(21,30) \mathrm{A}, \mathrm{ab}$ \\
\hline Imersão + Escovação & $10,92(11,39) \mathrm{A}, \mathrm{b}$ & $13,06(11,08) \mathrm{A}, \mathrm{b}$ \\
\hline
\end{tabular}

*Letras maiúsculas diferentes apresentam diferenças estatísticas na linha.

*Letras minúsculas diferentes apresentam diferenças estatísticas na coluna. 


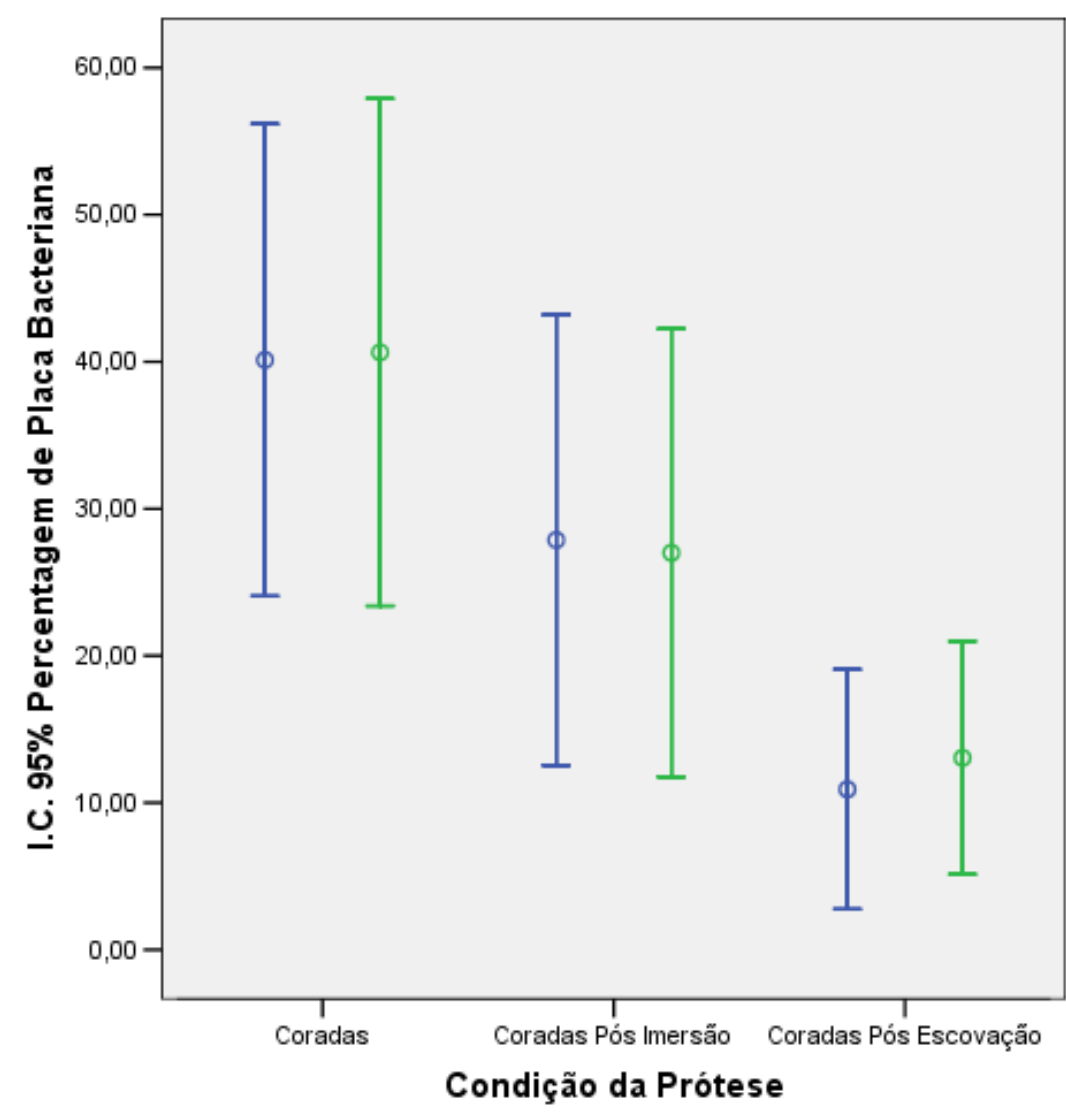

\section{DISCUSSÃO}

Os resultados do presente estudo sugerem que a correta higienização das próteses totais está diretamente relacionada à associação dos métodos químico e mecânico. Catão et al.;(2005) consideraram a prótese total o tratamento reabilitador mais utilizado em pacientes edêntulos, porém foi observado certa negligência por parte dos portadores quanto à higienização e manutenção dos aparelhos protéticos, como presenciado nesta pesquisa. Os produtos de higiene Corega Tabs e hipoclorito de sódio a 2,5\% não revelaram diferentes resultados na eficiência de remoção da placa bacteriana, o que sugere que a solução de hipoclorito de sódio pode ser bem indicada para pacientes usuários de próteses totais. Segundo Estrela et al (2002) o ph alcalino do hipoclorito de sódio interfere na integridade da membrana citoplasmática da bactéria provocando inibição enzimática.

Neste estudo foram encontrados $69,49 \%$ de placa bacteriana após a imersão em solução de Corega Tabs, reduzindo em $30,51 \%$ a quantidade de placa e $\mathbf{6 6 , 4 4 \%}$ após imersão em solução de Hipoclorito de sódio 2,5\%,reduzindo em 33,56\% o biofilme não estando de acordo com os resultados de Catão et al., (2007) que detectaram remoção $75 \%$ de biofilme após hipoclorito de sódio 2,25\% e 50\% após Corega Tabs. Este estudo variou os tempos de imersão que foram de 10 min para o hipoclorito de sódio e 5 min para 
o Corega Tabs, porém não utilizou o método de escovação. Segundo Kim et al.;(2003) a escovação da prótese é o primeiro passo para uma limpeza eficaz e a substância química de imersão é um coadjuvante no processo. Cruz et al (2005) também chegaram a resultados similares aos desta pesquisa. Compararam clinicamente a eficácia do método químico(pastilhas efervescentes) e do mecânico químico(pastilhas+ escovação) ou (hipoclorito + escovação ) na remoção do biofilme das próteses e concluiram que o combinado foi mais eficaz.

O método de avaliação selecionado nesse estudo para mensurar a quantidade de placa bacteriana foi o método da contagem de pontos com o auxílio da substância corante fuccina básica. Segundo Silva, Paranhos e Ito(2002) um evidenciador não pode ter propriedade bactericida e/ou bacteriana para não interferir nos resultado da pesquisa e mostraram que a fluosceina sódica, a eritrosina, a proflavina, a eosina, o vermelho neutro e o Replak podem ser utilizado com efetividade, apresentando afinidade com o biofilme e facilidade na remoção.

Silva e Seixas (2008) detectaram que o hipoclorito de sódio reduziu consideravelmente a adesão de várias espécies de Cândida nas próteses na concentração de $2,5 \%$ e na de 5,25\% promoveu esterilização, porém observaram manchamento do acrílico. Apesar de saber da importância da composição da placa bacteriana presente nas próteses totais removíveis, esta análise não foi objeto do presente estudo. Oliveira et al(2000) afirmam que as próteses muco suportadas são consideradas facilitadoras em potencial da estomatite protética sendo a mais comum a Candida albicans assim como Kulak, Kazazoglu, Arikan;(2002) também afirmam que uma boa higiene bucal é essencial para prevenir esta estomatite.

A orientação do paciente por parte do cirurgião-dentista quanto à escovação das próteses removíveis, assim como da língua, bochechas e palato é de extrema importância para evitar, além das estomatites, as doenças cardíacas e pulmonares(Santána et al 1992). Nesta pesquisa detectou-se que a região anterior e a de fundo de vestíbulo das bases das próteses, por serem retentivas, promovem um maior acúmulo de placa bacteriana. Esta observação sugere que o paciente possui dificuldades em escovar as áreas mais retentivas das bases das próteses totais removíveis superiores. 


\section{CONSIDERAÇÕES FINAIS}

Considerando-se as limitações do estudo pode-se concluir que:

- o método de higienização mecânico aliado ao químico é eficaz na higienização das próteses com a função de desagregar a placa bacteriana;

- para obter um resultado eficiente na higienização é necessário realizar a escovação da prótese após imersão;

- a solução de hipoclorito de sódio, por ser eficaz e de menor custo, pode ser recomendado para os pacientes usuários de próteses totais;

- a orientação dos pacientes sobre a necessidade de higienização das próteses totais, assim como a determinação do método de higiene são de responsabilidade do profissional da odontologia e de extrema importância para a melhora da qualidade de vida dos pacientes. 


\section{REFERÊNCIAS BIBLIOGRÁFICAS}

ALLEGRETTI ACV, SANTOS ZFDG. A vida familiar adulta. In: Moysér ST, Kriger L, Moysés SJ. Saúde bucal das famílias: trabalhando com evidências. São Paulo: Artes Médicas; 2008: 230-5.

CATÃO CD et.al. Eficiência de substâncias químicas na remoção do biofilme em próteses totais. Bras. Oral v.19 190 p (2005).

CRUZ.P.C. et al. Método químico-mecânico: comparação clínica na eficácia da remoção do biofilme da prótese totais.(Bras .Oral. Res.v.19,p.99) 2005.

ESTRELA C.et al. Mechanism of action of sodium hypoclorite. Oral Dent.J.(2002);13(2):113-7. (extraído da dissertação USP Bauru) COSTA E.J.( 2009 ).

FERNANDES, R. A. G.; ZANIQUELLI, O.; PARANHOS, H. de F. O. Análise dos métodos de contagem de pontos e planímetro na quantificação do biofilme da dentadura - um estudo de validação metodológica. Pesqui. Odontol. Bras., v. 16, n. 1, p. 63-68, jan. /mar. 2002.

FRANÇA, B. H. S.; SOUZA, A. M. Prevalência de manifestações estomatológicas originárias do uso de próteses totais. J. Bras. Clin. Int., Curitiba, v. 7, n. 40, p. 296-300, jul. lago. 2003.

GORNITSKY, M. et al. A clinical and microbiological evaluation of denture cleansers for geriatric patients in long-term care institutions. J. Can. Dent. Assoc., v. 69, n. 1, p. 39-45, 2002.

GOULART, Giovana et al. Avaliação dos hábitos de higiene bucal de pacientes das clínicas de prótese de faculdades de odontologia de Goiás. Rev. PCL, v. 6, n. 29, p. 45$\underline{53,2004 .}$

IBGE. http://www.ibge.gov.br/home/presidencia/noticias/noticia impressao.php?id noticia $=1272$.

KIM et al. the effect of a denture adhesive on colonization of candida species in vitro. Journal of Prosthodontics, n. 3, p. 187 - 91, sep. 2003.

KULAK YO, KAZAZOGLU E. ARIKAN A. Oral hygiene habits ,denture cleanliness; presence of yeasts and stomatitis in elderly people. Journal of Oral Reabilitation.;v. 29,p. 300-04, 2002.

LOVATO, C. H.; PARANHOS, H. de F. O.; ITO, I. Y. Aplicação clínica de evidenciadores de biofilme em próteses totais. RPG Rev. Pós. Grad., v. 7 n. 4 p. 311-319, out. /dez. 2000.

MINISTÉRIO DA SAÚDE. Departamento de Atenção Básica. Projeto SB Brasil 2003: condições de saúde bucal da população brasileira 2002-2003 - resultados principais. Brasília: Ministério da Saúde; 2004.

NIKAWA, $\mathrm{H}$. et al. A review of in vitro and in vivo methods to avaluate the efficacy of 
denture cleansers. Int. J. Prosthodont., v. 12, n. 2, p. 153-159, 1999.

OLIVEIRA, L. V. et al. The compatibility of denture cleansers and resilient liners. J. Appl. Oral. Sci., Bauru, v. 14, n. 4, p. 286-290, jul. /ago. 2006.

OLIVEIRA TCR, FRIGERIO M.L.M.A, YAMADA M.C.M, BERMAN EG. Avaliação de estomatite protética em portadores de prótese total. Pesquisa odontológica brasileira, v.14 p 219-24, jul/set 2000.

PARANHOS, H. F. O.; SILVA, C. H. L. Comparative study of methods for the quantification of biolfim on complete dentures. Braz. Oral. Res., v. 18, n. 3, p. 215-223, 2004.

SANT'ANA, A. T. et al. Higienização de prótese total pelo método mecânico.

Odonto - Caderno Documento, v.2, n.3, p.280-285, 1992.

SILVA, C. H. L.; PARANHOS, H. F. O.; ITO, I. Y. Evidenciadores de biofilme em prótese total: avaliação clínica e antimicrobiana. Pesqui. Odontol. Bras., v. 16 n. 3, p. 270-275, 2002.

SILVA, E. M. et al. Metodologia para quantificar indutos em pacientes portadores de prótese totais. Rev. Bras. Odont., v. 53, n. 1, p. 5-7, 1996.

SILVA e SEIXAS. Materiais e Métodos de Higienização para Próteses Removíveis. IDJ, 2008. 